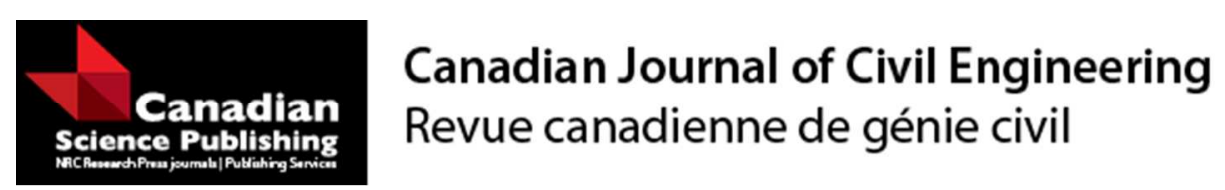

\title{
Examining Budget Policies for New and Existing Facilities: A System Dynamics Approach
}

\begin{tabular}{|r|l|}
\hline Journal: & Canadian Journal of Civil Engineering \\
\hline Manuscript ID & cjce-2015-0486.R3 \\
\hline Manuscript Type: & Article \\
\hline Complete List of Authors: & $\begin{array}{l}\text { Rashedi, Roozbeh; University of Waterloo, } \\
\text { Hegazy, Tarek; University of Waterloo, Civil \& Env. Engineering; University } \\
\text { of Waterloo, Civil \& Env. Engineering }\end{array}$ \\
\hline Keyword: & $\begin{array}{l}\text { System Dynamics, Policy Optimization, Capital Budgeting, Fund Allocation, } \\
\text { Facility Management }\end{array}$ \\
\hline \multicolumn{2}{|c}{} \\
\hline
\end{tabular}

\section{SCHOLARONE ${ }^{\text {m }}$}

Manuscripts 


\title{
Examining Budget Policies for New and Existing Facilities: A System Dynamics Approach
}

\author{
Roozbeh Rashedi ${ }^{1}$ and Tarek Hegazy ${ }^{2}$
}

\section{Corresponding Author}

PhD Candidate

Civil and Environmental Engineering Department

University of Waterloo

Waterloo, Ontario, N2L 3G1

Tel: (519) 888-4567 ext: 31172

E.Mail rrashedi@uwaterloo.ca

2. Professor

Civil and Environmental Engineering Department

University of Waterloo

Waterloo, Ontario, N2L 3G1

Tel: (519) 888-4567 ext: 32174

Fax: (519) 888-4349

E.Mail tarek@uwaterloo.ca

${ }^{1}$ PhD Candidate, Civil and Environ. Engrg. Dept., University of Waterloo, Waterloo, Ontario, N2L 3G1 Canada, Email: rrashedi@uwaterloo.ca.

2 Prof., Civil and Environ. Engrg. Dept., University of Waterloo, Waterloo, Ontario, N2L 3G1 Canada, Email: tarek@uwaterloo.ca 


\begin{abstract}
Sustaining acceptable service in large facility networks is a complex task, particularly under limited budgets, rapid deterioration, and increasing service demands. Policymakers are, therefore, challenged to make efficient balance between the construction of new facilities and the renewal of existing ones to suit both the short and the long-term needs. To support policy-makers, this paper proposes an efficient decision support system using the System Dynamics (SD) simulation technique to analyse the impact of various budget allocation policies and to optimize policy decisions. The proposed system dynamics model was tested using a case study from the Toronto District school Board involving more than 400 schools. It can find the optimum budgeting strategy that minimizes the overall facility condition index and total life cycle cost over a long-term strategic plan. The system dynamics model proved its ability to find a budget allocation policy with much better results than the typical enrolment-based approach.
\end{abstract}

Keywords: System Dynamics, Policy Optimization, Capital Budgeting, Fund Allocation, Facility Management, Asset Management 


\section{INTRODUCTION}

One of the key challenges for managing a large network of facilities is to preserve the performance of existing facilities and introduce new ones to modernize the inventory and accommodate additional service demands. From a strategic perspective, therefore, it is important to determine the optimum level of funds that should be allocated to the rehabilitation of existing facilities, as well as to the construction of new ones, particularly for the facilities that affect the health and welfare of citizens. At the strategic level of facility management, therefore, decisions must be made regarding rehabilitation budget limits, the level of allocated budget to rehabilitation, new construction, and maintenance, in addition to, examining various policy scenarios and their long-term impacts. Such difficult strategic decisions must be carefully analysed considering short-term and long-term needs and constraints. Among the important public facilities that are facing significant backlog and performance issues are school buildings. In the Unites States, the 2013 report card of America's infrastructure assigned a D (poor) grade to the school infrastructure, with a projected backlog of at least $\$ 270$ billion (ASCE 2013). Meanwhile, school enrolment is projected to gradually increase through 2019, while state and local funding continues to decline (ASCE 2013). In Canada, school administrators and facility managers are facing similar problems. The Toronto District School Board (TDSB), which is the largest school board in Canada, alone reported a $\$ 3.2$ billion capital renewal backlog with an increasing enrolment trend for the future (TDSB 2014) that requires substantial funding for new constructions. The large deficit and the need for new facilities, coupled with the deteriorated state of existing assets, necessitates novel approaches for determining optimum budgeting strategies.

In the literature, some efforts have attempted to address the above fund allocation 
problem. Johnstone (1995), for example, used an actuarial model to decide between rehabilitation and new construction, for each facility. The study, however, did not take a strategic long-term view of the analysis. In another example, Wilkins et al. (2015), compared the costs of producing multifamily housing through new construction or acquisition-rehabilitation over a 50-year life cycle and concluded that new constructions were associated with $25 \%$ to $45 \%$ higher lifecycle costs.

While new construction has its challenges, it applies to few facilities in some years. Rehabilitation, on the other hand, has to consider the whole existing inventory of facilities every year, which is very challenging, particularly under budget limits. Prioritizing all the components of all facilities for rehabilitation over a multi-year plan is not a simple task, particularly when the inventory has many old facilities. In the literature, researchers proposed decision support tools to help with rehabilitation fund allocation for various asset domains (e.g., bridges, pavements, buildings, etc.). Frangopol and Liu (2007), for example, proposed a model for prioritizing the rehabilitation of bridges by considering multiple criteria including condition and safety. Halfawy et al. (2008), proposed a GIS-based system to support the renewal planning of sewer networks considering costs, condition improvement, and risk reduction. For pavements, de la Garza et al. (2011) developed a pavement maintenance optimization subject to budget constraints and performance goals. In the facility domain, Rashedi and Hegazy (2014) compared mathematical and evolutionary optimization techniques to maximize the overall condition of more than 50,000 building components over a fiveyear plan. All these systems, however, work at the operational level, under a given budget limit. 
For strategic analysis, a powerful simulation concept, called System Dynamics (SD) was introduced in 1961by Forrester (1961). System dynamics modelling generally rests upon the idea of system thinking in which all strategic decisions take place in the context of dynamic feedback loops (Sterman 2001). Because of the promising results of SD-based simulation tools and models, they have been utilized in a variety of domains from construction to politics, and even warfare (Sterman 2000). In the area of construction management, Lee at al. (2006) used SD to improve the overall construction productivity and to analyse schedule changes. Alvanchi et al. (2011), also used SD and discrete event simulation to address the conceptual phase of hybrid SD-DES modelling for mega construction projects. In the facility management domain, Rashedi and Hegazy (2015) developed an SD model to analyse the dynamics of deterioration and rehabilitation mechanisms for a network of assets over 50 years.

Typically, decisions regarding budget limits are made at the strategic level, where many factors related to the strategic and operational dynamics of the whole asset network need to be considered. This paper thus proposes a decision support framework that utilizes the system dynamics (SD) simulation technique to examine the variety of factors that affect budget policy (for new and rehabilitation projects) and the consequent impact on the long-term performance of facilities and the consequent backlog accumulation.

\section{PROPOSED DECISION-SUPPORT FRAMEWORK}

Fig. 1 shows the three-step research methodology behind the proposed decision support framework. At its heart lies a system dynamics (SD) model that simulates the long-term behaviour of the key system parameters. In step 1, facility inventory data, such as facility condition index (FCI), age, facility gross floor area (GFA), etc., are inputs to the 
SD model, along with the long-term goals and performance indicators. The SD model is then developed and validated in step 2. Upon validation the SD model is then used to simulate the long-term effects of various strategic policies in step 3. In this step, the simulation dashboard allows the user to change several policy parameters and see the real-time impact on various performance indicators. The SD model can also be used to determine the optimum budgets for new construction and rehabilitation actions that maximize various performance parameters for the network of facilities over a long-term strategic plan (e.g., 30 years). Details of the developments made in these three steps using data from the Toronto District School Board (TDSB) in Canada which administers more than 550 schools in Toronto are discussed in the following sections.

[Fig. 1: Research methodology for the proposed SD-based decision support framework]

\section{STEP 1 - DATA PREPARATION}

To build the simulation model, datasets regarding the overall operating condition of around 438 elementary schools, administrated by TDSB, have been used. The facilities have been categorize in a hierarchical manner based on building system (e.g., Architectural, mechanical, electrical, etc.), subsystems (e.g., exterior closures, HVAC, etc.) and components (e.g., windows, fire alarm, etc.). Periodic condition assessments data and deterioration information were also available for these assets from previous studies by the authors on this network with a relative importance factor for different components based on expert interviews (more information regarding TDSB asset network can be find on Rashedi and Hegazy (2014)). Annual TDSB reports regarding their facilities' condition and financial plans have been also used for model preparation. A measure of the performance of a facility $j$ at time $t$ is first determined using an 
industry standard measure called the Facility Condition Index (FCI), which is represented as follows:

$F C I_{j t}=\frac{\text { Renewal Backlog of Facility } j \text { at time } t}{\text { Facility } j \text { Replacement Cost }}$

Thus, FCI represents a facility need for renewal. A lower FCI value then represent a better facility performance and vice versa. Using linguistic terms for different ranges of FCI, the following (Rush 1991) can be defined:

- $0<\mathrm{FCI}<5$ represents a facility in 'good' condition

- $5<\mathrm{FCI}<10$ represents a facility in 'fair' condition

- $10<\mathrm{FCI}<30$ represents a facility in 'poor' condition

- $\quad \mathrm{FCI}>30 \quad$ represents a facility in 'critical' condition

- $\quad$ FCI $>65$ represents a facility that is 'Prohibited to Repair (PTR)'

The last category (PTR) was added by the Ministry of Education (TDSB 2014) for the facilities that are deemed financially infeasible to be renewed as the renewal cost is too high. The possibility of selling these properties and the overall impact on the asset network is an important debate in the education sector (TDSB 2014; TDSB 2007). Overall, the distribution of the FCI for TDSB facilities (assessed in 2007) is shown in Fig. 2. 84\% of the facilities are in 'poor' or 'critical' conditions (TDSB 2007) and the overall average FCI of the whole inventory is $20 \%$, representing an overall 'poor' condition. Using this information, the key challenge at the strategic level is to determine the level of budget to be allocated to new construction versus renewal work so that the overall FCI is brought to an acceptable level.

[Fig. 2: FCI distribution for TDSB facilities] 
In addition to detailed facility data, key strategic decision variables need to be determined prior to development of the strategic SD model. In the case of TDSB facilities, a total of 30 key decision parameters and policy options have been identified as shown in Table 1, based on information in their annual reports and published data. The table also provides a brief description for each parameter in addition to their relationships, which are discussed in details in the following section.

\section{STEP 2 - SD SIMULATION}

\section{Causal Loop Diagram}

As a first modelling step toward SD simulation, a causal loop diagram (CLD) has been developed to identify the main dynamic interactions and feedback loops in the system. A CLD consists of variables connected by causal links whose polarities denote the effects of one variables on another. A positive link, i.e., $(+)$ polarity, implies that the cause and effect are moving/changing in the same direction: e.g., if a cause increases, the effect increases, and if a cause decreases, the effect decreases. A negative link, i.e., (-) polarity, means that the cause and effect are moving/changing in opposite directions in the model (Sterman 2000). The developed CLD for the case study (Fig. 3) considers all the dynamic relations among of the key parameters (listed in the last column of Table 1). Key policy decision variables are highlighted in bold red text in Fig. 3.

\section{[Table 1]}

[Fig. 3: Proposed causal loop diagram (CLD)]

In the CLD of Fig. 3, combination of causal links create feedback loops that generally are positive $(+)$ or negative (-). Positive loops (also called reinforcing loops) generate 
growth behaviour while negative loops (also called balancing) generate goal seeking or equilibrium behaviour. The interaction amongst the feedback loops is the key to generating complex dynamic behaviours (Sterman 2001). A total of 71 feedback loops can be identified in Fig. 3. As examples, three highlighted loops reasonably model the rehabilitation (L1), new construction (L2), and maintenance (L3) processes. In loop L1, for instance, more rehabilitation actions reduce backlog and consequently FCI (as indicated in Eq. 1). In turn, lower FCI will result in a lower risk index that reduces the pressure on authorities to increase rehabilitation budget. Accordingly, the level of rehabilitation budget (i.e., '\% Rehab. Budget' in Fig. 3 and Table 1) will be reduced and will result in a lower rehabilitation budget, thus less rehabilitation actions. This negative (balancing) feedback loop seeks the goal of adjusting rehabilitation actions (and budget) based on a desired FCI level determined by facility managers or other authorities. Loops L2 and L3, on the other hand) can be studied in the same manner as loop L1 using the polarity of causal links depicted in Fig. 3. The objective of the negative loop L2 is to adjust the amount of new construction based on the capacity of existing schools and the total enrolment (see 'over-capacity' parameter in Table 1), while L3 is to adjust routine maintenance based on the maintenance needs of existing school buildings. It is important to note that in loop L2, 'New Construction' is linked to 'Total No. of Schools' by a positive link with a delay mark ' $\|$ ' (see red links in Fig. 3). Since construction of a new school can take considerable amount of time (e.g., 5 years for design development, approvals, and construction), the effect of this delay has been taken into account in the model by using a delay link and a delay function. 


\section{Stock and Flow Simulation Model}

The development of an SD model requires mapping of the proposed CLD dynamics into a stock and flow model, which is comprised of four main components: stocks, flows, valves, and clouds. The diagramming notations for these components are shown in Fig. 4. Stocks (rectangles) are accumulations of key system variables over the simulation time. Flows, on the other hand, generate quantities that go into a certain stock as "inflows", or go out of the stock as "outflows" over time. Valves are flow generators (based on the relations in the model) and control the amount of inflow and outflow over the simulation time. Clouds also represent entry or exit boundary points in the model.

[Fig. 4: Stock and flow diagramming notations]

Equations 2 and 3 below represent the basic mathematics behind stock and flow calculations. In general, the rate of change in a stock variable is determined based on the difference between the inflows and outflows (Eq. (2)). The value of a stock variables at any time t over the simulation time can be also determined using Eq. (3).

$\frac{d(\text { Stock })}{d t}=\operatorname{Inflow}(t)-$ Outflow $(t)$
$\operatorname{Stock}(t)=\int_{t_{0}}^{t}[\operatorname{Inflow}(s)-\operatorname{Outflow}(s)] d s+\operatorname{Stock}\left(t_{0}\right)$

Fig. 5 shows the proposed stock and flow simulation model developed based on the CLD of Fig. 3. Table 2 also provides a summary of key parameters presented in the proposed SD model and their equations in the model. It is important to note that for presentation purpose, some of the intermediate variables used in model calculations are not shown in Fig. 5 and only the key parameters are presented. Fig. 5a shows the central stock and flow model that simulates the process of FCI changes in the system, where 
the five FCI states are represented as five stocks that accumulate the number of schools in good, fair, poor, critical, and PTR states, respectively. The figure also shows two flows that represent two rehabilitation actions that improve FCI from poor to fair (Rehab. Level 1) and from critical to fair condition (Rehab. Level 2). To simulate new construction, an inflow is linked directly to the stock for $\mathrm{FCI}_{\mathrm{Good}}$ (left side of Fig. 5a). Also, an outflow from the $\mathrm{FCI}_{\mathrm{PTR}}$ stock is used to simulate the selling of old facilities. Furthermore, the deterioration from each FCI sate (stock) to a lower state is simulated by flows such as D12 (deterioration from $\mathrm{FCI}_{\mathrm{Good}}$ to $\mathrm{FCI}_{\mathrm{Fair}}$ ). Details of the FCI calculations are presented in Table 2. In the proposed model, maintenance affects deterioration rates by using a variable called 'maintenance factor' (MF). In the model, maintenance reduces the deterioration rates, thus, reduces the rate by which FCI worsens with time (see Table 2 'DR12').

[Fig. 5: Proposed stock and flow simulation model]

In the $\mathrm{SD}$ model of Fig. 5b, three key variables represent the main performance indicators that need to be monitored throughout the simulation: overall facility condition index (FCI); overall facility risk index (FRI), and the total life cycle cost (TLCC). Table 2 provides their corresponding equations. The overall FCI is a weighted average determined based on the distribution of facilities in different FCI states. Overall FRI is also determined based on the probability of failure of the facilities in different FCI states, network over-capacity, and the age of the facility network. As suggested by FRI equation in Table 2, FRI is higher when the network age is older (i.e., no new schools are added) and when the schools are overpopulated. The TLCC is accumulated in a stock at the bottom of Fig. 5b. Additionally, since the whole budget might not be fully 
consumed in a simulation year, a stock variable 'Residual Fund' has been added to reinvest the unused funds in the following year (see bottom left part of Fig. 5b). Another key variables in the model that directly affect the deterioration process are the deterioration flows (e.g., D12 in Table 2). The flow values are governed by the transition probability between FCI states in addition to the level of maintenance. To determine a reasonable value for the transition probabilities, previous research on the deterioration modelling of building facilities (Elhakeem and Hegazy 2012) has been used to reasonably estimate and to provide adequate constraints on the deterioration process for the pool of facilities based on the previously observed reference modes. The rates are then calibrated and tested based on these constraints and observed FCI trends to ensure adequacy as discussed in the following section.

[Table 2]

\section{MODEL IMPLEMENTATION \& VALIDATION}

Testing and validation of SD models is an important part of model development (Sterman 2002). In this paper, therefore, upon the development of the SD model for the TDSB case study involving 438 school buildings, various validation tests have been conducted. Facility replacement costs, new construction costs, network age, and other assumptions have been made based on TDSB and Ministry of Education reports on school buildings. The SD model was then implemented using a commercial SD simulation tool, VENSIM ${ }^{\circledR}$, and all of the parameters and equations in Tables 1 and 2 were input to the software to perform simulation tests and later policy optimization. 


\section{Calibration of Deterioration Rates}

A set of FCI values representing actual data over a 10-year period was used for model calibration (Figure 6). Calibration has been done using optimization with an objective of minimizing the error between the projected FCI values and those of actual data by adjusting deterioration rates. During the calibration process, specific constraints were applied to ensure that the rates are in accordance with the previous study on the building facilities deterioration models and also the three-phase deterioration process defined in asset management books (e.g., Hudson et al. 1997). The result of DR calibration suggest values of $0.1,0.158,0.135$, and 0.187 for DR12, DR23, DR34, and DR45, respectively. Detailed analysis of possible variations in the transition probabilities has also been conducted using multivariate Monte Carlo analysis to investigate the impact of possible variations on the recommend policies (use of multivariate Monte Carlo analysis is discussed in the later part of this section). Results of this analysis clearly indicated that the possible variation can affect the confidence bound of the long-term behaviours, however, the overall trend are very consistent and there is no sign of significant impact on the policy recommendations. The used rates are therefore the acceptable results for the deterioration modelling at the strategic level based on the available data. This, however, is a current limitation of the developed SD model and with more accurate and consistent data collection deterioration model and corresponding results can be further improved.

[Fig. 6: Calibration of deterioration rates (DRs)]

\section{Dimensional Consistency \& Structure Assessment}

One of the useful features of VENSIM $®$ is that it can perform dimensional consistency test as long as all variable units are defined, which was satisfied in the present case 
study. The software also includes several tools such as 'cause/effect trees' that can be utilized to analyse the model relationships at different hierarchical levels. For example, 'Overall FCI' can be selected as a target variables and then by generating a tree structure it is possible to check the variables affecting 'Overall FCI' at different levels with the direction of their impact (i.e., positive or negative). Using such diagrams, a process was followed to verify all the relations in the proposed SD model.

\section{Model Conditions and Dynamic Input Tests}

As part of model testing, it was subjected to several condition tests that must hold true over the simulation process. For example, FCI values should always be between 0 and 100 , or the total life cycle cost (TLCC) must be less than or equal to the accumulated capital budget (CAPBUD). These logical conditions ensure that all relationships are adequate. To perform these tests, the Reality Check ${ }^{\circledR}$ feature of the VENSIM software was used. In another set of experiments, the model was subjected to various dynamic input tests (DITs) to examine its robustness and response to sudden dynamic changes and extreme conditions. Fig. 7 shows the results of a series of tests in which a base CAPBUD of $\$ 80$ million was subjected to various dynamic inputs, including STEP, RAMP, and PULSE inputs, and model response was recorded in terms of FCI.

[Fig. 7: Model response to dynamic input tests]

Fig. 7a shows a ramp input (red dashed line) that sets CAPBUD to zero for the first 10 years and then slopes upward to its full value over a 10 year period (form year 10 to 20). In this experiment, the steady increase of CAPBUD reduces the slope of FCI curve gradually, as expected. Fig. $7 \mathrm{~b}$ also shows a sudden step changes in the value of CAPBUD which results in a sudden reduce of FCI slope. Fig. 7c shows model response 
to a pulse input effective form year 10 to 20 . As shown in the figure, over the pulse period FCI is maintained without deterioration, while after the sudden drop at year 20 it starts to increases. In all of the DITs, model behaviour was consistent with logical expectations without any anomalous behaviour. Also all model conditions are checked simultaneously with DITs for possible violations to ensure model's robustness and adequacy under extreme conditions

\section{Sensitivity Analysis}

Due to the uncertainty involved in some of the model assumptions and numerical parameters, multi-variate Monte Carlo sensitivity-analysis were performed to check the impact of possible variations in these parameters on key performance indicators to ensure the robustness of the model conclusions. In one set of experiments, effects of variations in two cost-related and uncertain parameters have been investigated: average facility replacement cost $(\$ F R C)$ and facility maintenance need $(\$ M N)$. The initial model values for $\$ F R C$ and $\$ M N$ were set to $\$ 10 M$ and $\$ 100 \mathrm{~K}$, respectively, which are close to the real numbers used at the TDSB. A $30 \%$ variation is then used for both parameters to test FCI and FRI projections as shown in Fig. 8a,b which shows the results of sensitivity analysis tests within $50 \%, 75 \%, 95 \%$, and $100 \%$ confidence bounds. This variation produced a range of values for FCI and FRI, however, the pattern of behaviour of FCI and FRI did not seem to be affected by the $30 \%$ uncertainty level, thus the impact of uncertainty is not likely to affect the policy recommendation significantly. Based on these experiments, the current values can be presumed to be reasonable for the purpose of policy simulation.

[Fig. 8: Multi-variate sensitivity analyses results for FRI] 


\section{STEP 3 - EXPERIMENTS, REPORTING, AND OPTIMIZATION}

\section{Policy Simulation Dashboard}

Using the customization features of VENSIM, a policy simulation dashboard has been developed with a user-friendly interface that enables a policymaker to setup various policy scenarios and investigate their impact on key performance indicators (Fig. 9). A series of sliders representing the value of various policy-related parameters are shown on the left side of the dashboard. By changing the value of these parameters, a policymaker can create various policy scenarios and see their real-time impact on performance indicators shown by the output graphs of the dashboard. This can significantly help a policy-maker to get a deeper understating of system's behaviours and the effectiveness of various policy scenarios. In addition to its use for strategic decision-making and policy optimization, such decision support tool (DST) can be very useful in high-level analysis, and allows individuals with little or no training in modelling to get meaningful access to the model.

[Fig. 9: Policy simulation dashboard]

\section{Analysis of Enrolment-Based Budgeting Policy}

One of the common practices for education ministries is to authorize capital budget for school boards based on the expected enrolment (TDSB 2014). This means more budget is authorized when enrolment is increasing and less as enrolment drops. Using the proposed SD model, this enrolment-based budgeting policy is investigate by simulating the effect of five different enrolment trends (Fig. 10a): a constant trend (T1-Cnt); an increasing trend (T2-Inc); a declining trend (T3-Dec); a variable trend starting with an increasing rate followed by a decline (T4-Var); and a variable declining trend followed 
by a sharp increase (T5-Var). Capital budget is set based on an initial enrolment of 154,600 students and a $\$ 516$ annual budget per students (this assumed number is close to reality based on available data from TDSB). Fig. 10b shows the resulting capital budget (CAPBUD) based on an enrolment-based budgeting policy.

[Fig. 10: Effect of enrolment-based budgeting policies]

An overall look at the FCI results in Fig. 10c indicates that in all scenarios the FCI tends to increase over time, suggesting that the current level of budget is not adequate. One of the key problems with enrolment-based budgeting is in the case of declining enrolment. As enrolment declines, allocated capital budget is reduced, although the number of deteriorated facilities and their rehabilitation needs does not change. Thus, the reduced budget becomes inadequate and can result in an accelerated deterioration process over time (see T3-Dec in Fig. 10c). In the case of increasing trend, it can be seen that overall FCI reaches an equilibrium at around 38\%, however, overall FRI is now increasing over time mainly due to over-capacity. From a general perspective and with regard to the main feedback loops in the model, the equilibrium state of FCI can be related to the dominance of the balancing (negative) 'Rehabilitation' loop (L1) over the simulation horizon due to the increase in rehabilitation budget and consequently higher number of rehabilitation actions. On the other hand, risk has been increased over time since the balancing 'New Construction' loop (L2) cannot subside the effect of increasing enrolment trend on over-capacity, because of the inadequate budgeting for new constructions. The worst situation in these experiments is a combination of a declining enrolment and a sharp increase in enrolment (this can happen due to residential intensification for example). As shown in Fig. 10c,d, this results in the worst 
performance in terms of FCI and FRI. In this case, due to the diminished budget in the first 15 years, the network condition is getting critical (Fig. 10c). When the enrolment trend is shifted in around year 15, now a seriously deteriorated network does not have the capacity to accommodate the increasing enrolment and results in a high level of risk and poor performance. The experiments presented in this section, showed the usefulness of the proposed framework in analysing strategic policies. Furthermore, the results of enrolment-based budgeting polices clearly indicate that this policy can result in poor facility performance over time as it ignores a variety of dynamics within the system.

\section{Optimum Budgeting Policy}

This section presents a set of policy optimization experiments seeking best policy solutions to achieve strategic objectives and a satisfactory performance level. The enrolment trend 'T5-Var' was used in optimization experiments to determine the optimum budget levels and budget allocation strategies to improve performance in terms of FCI and FRI. As indicated in Eq. (4), the optimization model is set up to minimize an objective function that combines three weighted performance indicators: FCI, FRI, and TLCC. Since high percentage of over-capacity is not acceptable in the case of school buildings, the objective function in the optimization has to a penalty function representing over-capacity, formulated in Eq. (5). The decision variables of the optimization experiments are presented in Eq. (6), where, \% $\mathrm{NC}$ is the percentage of capital budget (CAPBUD) allocated to new construction; \%Rehab is the percentage of CAPBUD allocated to rehabilitation; \%RL1 is the percentage of rehabilitation budget allocated to rehabilitation level 1; \%RL2 is the percentage of rehabilitation budget allocated to rehabilitation level 2; MF is the maintenance factor ranging from 0.1 to 1 ; and CAPBUD is capital budget ranging from 0 to $\$ 200$ million. 
Objective: Minimize $Z=w_{1} \cdot F C I+w_{2} \cdot F R I+w_{3} . T L C C+$ Penalty

Penalty for overcapacity $=w_{4} \cdot\left[\operatorname{Max}\left(U R_{t}-1,0\right)\right]$

Decision Variables: $\left[\% N C_{t}, \% R e h a b_{t}, \% R L 1_{t}, \% R L 2_{t}, M F, C A P B U D_{t}\right]$

All decision variables that represent budget levels were analysed over 5-year intervals until the end of the 30-year strategic plan to dynamically identify the optimum values during each interval. The value of weights $w_{1}, w_{2}, w_{3}$, and $w_{4}$ are set to $0.6,0.2,0.2$, and 1, respectively. These weights were identified through an iterative process such that they adequately reflect the contribution of each parameter in the objective and penalty functions. Also, the values for FCI, FRI, and TLCC are normalized into a similar scale to avoid bias toward a specific parameter. The model then utilizes an efficient Powell hill climbing algorithm used by VENSIM ${ }^{\circledR}$ to search through a large simulation space to minimize the objective function, while identifying the optimum budget levels for new construction, rehabilitation, and maintenance over a 30-year strategic plan. Fig. 11 shows the policy optimization results. As shown in Figure 11,a,b, both FCI and FRI are significantly improved as compared to the enrolment-based budgeting policy. Renewal backlog and the overall FCI have been reduced and remained at around 19\% over the strategic plan, showing a $60 \%$ improvement as compared to the enrolment-based policy. Likewise, FRI showed a $74 \%$ improvement as compared to the enrolment-based policy with a small increase in value over the strategic plan.

[Fig. 11: Policy optimization results]

Fig. 11c shows the optimized CAPBUD level, which is determined to be higher than the enrolment-based policy. As shown in Fig. 11c,d, prior to the shift in the enrolment trend 
from decreasing to increasing, the budget is accumulated to spend on new constructions to accommodate future enrolment and to avoid over-capacity. The actual capital expenditure (CAPEX) is shown in Fig. 11d. CAPEX is composed of three costs including new construction, rehabilitation, and maintenance. In the first five years, the majority of CAPEX is spent on rehabilitation and maintenance. Policy optimization also resulted in a value of 1 for maintenance factor recommending full maintenance over the entire plan. Maintenance cost, which is determined based on the number of schools and maintenance needs, stays at around $\$ 43$ million until year 25 and gradually increases as new schools are added to the network. At around year 20, there is a peak in CAPEX due to large new construction expenditures (Fig. 11d). The model observes the enrolment trend and the current capacity of the schools, which is around 190,000 students, and allocates substantial amount of budget to new construction considering a 5-years delay for construction to be done. Accordingly, new schools will be in service at around year 26 when enrolment is above the current capacity (see T5-Var trend in Fig. 10a). It is also possible to distribute new construction spending over a larger period to relax this peak of expenditure. The important insight from Fig. 11d, however, is that the model clearly indicates the need for new construction, suggests a level of spending, and shows when is the latest time over the plan to start new constructions.

Fig. 11e shows the value of the main budget allocation variables over the strategic plan. As discussed before, majority of CAPBUD is allocated to rehabilitation and maintenance until around year 20 when new construction is started. Also in the first 5 years of the plan, the optimum budgeting policy recommends using rehabilitation level 2 (major rehabilitation from critical to fair condition) more than rehabilitation level 1 , suggesting an immediate major rehabilitation action. After year 5 , policy optimization 
results suggest more spending on rehabilitation level 1 than level 2. Fig. $11 \mathrm{f}$ also shows a comparison between FCI distribution in the beginning and at the end of the strategic plan. As shown in this figure, the number of facilities in good condition remains almost the same by constructing new facilities over the plan. Also, the number of facilities in fair condition is much higher and the number of facilities in poor condition is significantly reduced. The number of facilities in critical condition is also slightly reduced. This is due to the fact that some facilities are deemed PTR, so they will not be repaired over the plan. Selling these facilities can have a substantial positive impact on the overall performance, however, it has a negative impact on total school capacity. Selling PTR facilities that are under-enrolled and its impact on the school boards is a point of debate in education sector. Analysing the local impact of selling these facilities from a social or real-state point of view is beyond the scope of this paper, however, the proposed model can analyse and show the impact of selling PTR facilities on several performance indicators. By adding ' $\%$ Sell' to decision variables, policy optimization results showed that by selling PTR facilities, overall FCI improved from 19.4 to 11.3 and FRI from 0.057 to 0.021 . Also the number of facility in critical condition significantly reduced from $20 \%$ to only $6 \%$.

\section{CONCLUDING REMARKS}

This paper presented a novel System Dynamics (SD) model to analyse the impact of various budgeting policies for the rehabilitation of deteriorated facilities versus the construction of new facilities. Detailed discussion on how to develop, test, and validate a system dynamics model were presented in the paper. The proposed dynamic hypothesis were illustrated in a causal loop diagram (CLD), and was then mapped into a stock and flow simulation model with all the underlying relationships and mathematical formulations. A rigorous model testing and validation procedure was then presented that 
entailed various tests and sensitivity analyses to verify the developed SD model. The model was then used to perform policy optimization in order to determine optimum budget levels for new construction, rehabilitation, and maintenance, using a case study involving more than 400 schools from the TDSB asset inventory. Simulation results clearly indicated that the enrolment-based budgeting policy, which has been used by education ministries, is not an effective strategy, specifically in the case of declining enrolment trends. This policy can result in significant deterioration and backlog in addition to a high level of risk when a shift in enrolment trends happens. Consequently, using the proposed model, budget allocation variables were optimized, considering both rehabilitation of existing facilities and construction of new ones, and resulted in significant improvement of the overall facility condition index (around 60\%).

As a future extension to the model, it can be integrated with other tactical/operational fund allocation optimization models to devise effective and detailed fund allocation plan for individual facilities. Other aspects such as school locations, residential intensification, and the social impacts of budgeting policies can be also added to the model. With the use of consistent periodic facility monitoring and condition assessment, the deterioration model can be further calibrated over time to further improve its performance and policy projections. Overall, the promising results of policy optimization and the usefulness of the model as a strategic decision support tool proved the potential and effectiveness of using system dynamics in strategic management. The proposed SD model is also a versatile tool that can be used in other asset domains to assist asset managers in analysing the long-term impact of various policy scenarios and to find optimum facility management solutions. 


\section{REFERENCES}

Alvanchi, A., Lee, S., \& AbouRizk, S. 2011. Modeling framework and architecture of hybrid system dynamics and discrete event simulation for construction. ComputerAided Civil and Infrastructure Engineering, 26(2), 77-91.

ASCE (American Society of Civil Engineers) 2013. America's Infrastructure Report $\begin{array}{lllll}\text { Cards } & - & \text { Schools, } & \text { Available from }\end{array}$ http://www.infrastructurereportcard.org/a/\#p/schools/overview/ [accessed 2015].

de la Garza, J., Akyildiz, S., Bish, D. and Krueger, D. 2011. Network-level optimization of pavement maintenance renewal strategies. Advanced Engineering Informatics 25 (4), 699-712.

Elhakeem, A. and Hegazy, T. 2012. Building asset management with deficiency tracking and integrated life cycle optimization. Structure and Infrastructure Engineering. 8(8), 729-728.

Forrester, J.W. 1961. Industrial Dynamics. Cambridge: MIT Press, Currently available from Pegasus Communications: Waltham, MA.

Frangopol, D.M., Liu, M. 2007. Maintenance and management of civil infrastructure based on condition, safety, optimization, and life-cycle cost. Structure and Infrastructure Engineering, 3(1), 29-41.

Halfawy, M. , Dridi, L., and Baker, S. 2008. Integrated Decision Support System for Optimal Renewal Planning of Sewer Networks, Journal of Computing in Civil Engineering, ASCE, 22 (6), 360-372.

Hudson, W.R., Hass, R., \& Uddin, W. 1997. Infrastructure management. New York, NY: McGraw-Hill.

Johnstone I. M., 1995. An actuarial model of rehabilitation versus new construction of housing. Journal of Property Finance, 6(3), 7-26.

Lee, S. H., Peña-Mora, F., \& Park, M. 2006. Dynamic planning and control methodology for strategic and operational construction project management. Automation in Construction, 15(1), 84-97.

Rashedi, R., \& Hegazy, T. 2014. Capital renewal optimisation for large-scale infrastructure networks: genetic algorithms versus advanced mathematical tools. Structure and Infrastructure Engineering, 11(3), 253-263.

Rashedi, R., \& Hegazy, T. 2015. Holistic Analysis of Infrastructure Deterioration and Rehabilitation Using System Dynamics. Journal of Infrastructure Systems, ASCE, DOI: 10.1061/(ASCE)IS.1943-555X.0000273, 04015016.. 
Rush S. C. 1991. Applied Management Engineering: a practical approach to institutional facility renewal and deferred maintenance. Coopers \& Lybrand National Association of College and University Business Officers, Business \& Economics.

Sterman, J.D. 2000. Business Dynamics: Systems Thinking and Modeling for a Complex World. Boston: Irwin/McGraw-Hill.

Sterman, J.D. 2001. System dynamics modeling: Tools for learning in a complex world. California Management Review, (4), 8-25.

Sterman, J.D. 2002. All models are wrong: reflections on becoming a systems scientist. System Dynamics Review, 18(4), 501-531.

TDSB (Toronto District School Board) 2007. Facility Service Review, Blackstone Partners in Partnership with RMI Group Inc., January 2007.

TDSB (Toronto District School Board) 2014. Toronto District School Board Capital Facts: Building Strong and Vibrant School Communities, June 2014.

The Canadian Infrastructure Report Card 2012. The 2012 Report Card, Available from http://www.canadainfrastructure.ca/en/index.html/, [accessed 2015].

VENSIM 2007. User's Guide Version 5, Ventana Systems, Inc. Revision Date: July 4, 2007.

Wilkins, C., Brennan, M., Deora, A., Heegaard, A., Lee, A., Lubell, J. 2015. Comparing the Life-Cycle Costs of New Construction and Acquisition-Rehab of Affordable Multifamily Rental Housing. Housing Policy Debate, 25(4), 684-714. 


\section{List of Tables}

Table 1: CLD parameters, their relationships, and description.

Table 2: Key parameters and equations of the stock-and-flow simulation model 
Table 1: Model parameters and their relationship to each other.

\begin{tabular}{|c|c|c|c|}
\hline No. & Parameter Name & Description/Assumption & Governing Parameters \\
\hline 1 & $\%$ Sell PTR & Percentage of PTR schools to sell each year & No. of PTR schools \\
\hline 2 & $\%$ New Construction Budget & $\begin{array}{l}\text { Percentage of total budget allocated to new } \\
\text { construction each year }\end{array}$ & $\begin{array}{l}\text { \%Rehab. Budget, Pressure to Build } \\
\text { New Schools }\end{array}$ \\
\hline 3 & \%Rehab. Budget & $\begin{array}{l}\text { Percentage of total budget allocated to } \\
\text { rehabilitation (renewal) each year }\end{array}$ & $\begin{array}{l}\text { \%New Construction Budget, Pressure } \\
\text { to Increase Rehab. Budget }\end{array}$ \\
\hline 4 & Capital Budget (CAPBUD) & $\begin{array}{l}\text { Total capital budget, determined based on } \\
\text { enrolment }\end{array}$ & $\begin{array}{l}\text { Income from Sold Property, Total } \\
\text { Enrolment }\end{array}$ \\
\hline 5 & Deterioration Rate & $\begin{array}{l}\text { Higher maintenance means lower } \\
\text { deterioration rate }\end{array}$ & Routine Maintenance \\
\hline 6 & Facility Age & Average age of the whole facility network & New Construction \\
\hline 7 & FCI & $\begin{array}{l}\text { Overall average Facility Condition Index of } \\
\text { all facilities }\end{array}$ & New Construction, Rehab. Backlog \\
\hline 8 & Income from Sold Property & $\begin{array}{l}\text { Depends on the number of sold properties } \\
\text { and their expected value }\end{array}$ & $\%$ Sell PTR \\
\hline 9 & Maintenance Budget & $\$$ amount of budget for maintenance & $\begin{array}{l}\text { Maintenance Factor, Maintenance } \\
\text { Needs }\end{array}$ \\
\hline 10 & Maintenance Factor & $\begin{array}{l}\text { A factor between } 0.5 \text { to } 1 \text { representing the } \\
\text { level of maintenance work relative to needs }\end{array}$ & N/A (Exogenous) \\
\hline 11 & Maintenance Needs & $\begin{array}{l}\text { Depends on the total school Gross Floor } \\
\text { Area (GFA) and level of maintenance }\end{array}$ & $\begin{array}{l}\text { Routine Maintenance, Total School } \\
\text { GFA }\end{array}$ \\
\hline 12 & New Construction & Number of new facilities to built & New Construction Budget \\
\hline 13 & New Construction Budget & $\begin{array}{l}\$ \text { amount of budget that goes to new } \\
\text { construction }\end{array}$ & $\begin{array}{l}\text { \%New Construction Budget, Renewal } \\
\text { Budget }\end{array}$ \\
\hline 14 & Over-Capacity & $\begin{array}{l}\text { A measure of the number of students versus } \\
\text { the capacity of schools }\end{array}$ & Total Enrolment, School Capacity \\
\hline 15 & Population Growth & Can affect enrolment trends & N/A (Exogenous) \\
\hline 16 & $\begin{array}{l}\text { Pressure to Build New } \\
\text { Schools }\end{array}$ & $\begin{array}{l}\text { A soft parameter representing the pressure } \\
\text { on authorities to build new facilities }\end{array}$ & Over-Capacity \\
\hline 17 & $\begin{array}{l}\text { Pressure to Increase Rehab. } \\
\text { Budget }\end{array}$ & $\begin{array}{l}\text { A soft parameter representing the pressure } \\
\text { on authorities to increase rehab. budget }\end{array}$ & Risk \\
\hline 18 & PTR & Number of prohibitive to repair facilities & FCI \\
\hline 19 & Rehab. Actions & Rehabilitation intervention over the plan & Rehab. Budget \\
\hline 20 & Rehab. Backlog & $\begin{array}{l}\text { Required investment to bring network into a } \\
\text { satisfactory level of performance }\end{array}$ & Rehab. Actions, Rehab. Needs \\
\hline 21 & Rehab. Budget & $\$$ amount of budget that goes to rehab. & \%Rehab. Budget, Renewal Budget \\
\hline 22 & Rehab. Needs & $\begin{array}{l}\text { As facilities age and deteriorate, more are in } \\
\text { critical state with rehab. needs }\end{array}$ & $\begin{array}{l}\text { Deterioration Rate, Total School } \\
\text { GFA }\end{array}$ \\
\hline 23 & Renewal Budget & $\begin{array}{l}\text { An intermediate variable determining the } \\
\text { portion of CAPBUD going to both rehab } \\
\text { and new construction }\end{array}$ & Capital Budget, Maintenance Budget \\
\hline 24 & Residential Intensification & Can significantly affect enrolment trends & N/A (Exogenous) \\
\hline 25 & Risk & $\begin{array}{l}\text { Facilities in critical condition, older, and } \\
\text { over-populated contribute more to the } \\
\text { overall risk of failure. }\end{array}$ & FCI, Facility Age, Over-capacity \\
\hline 26 & Routine Maintenance & Maintenance operations over the plan & Maintenance Budget \\
\hline 27 & School Capacity & $\begin{array}{l}\text { Determined based on the average capacity } \\
\text { of schools }\end{array}$ & Total No. of Schools \\
\hline 28 & Total Enrolment & $\begin{array}{l}\text { Depends on demographic changes or } \\
\text { projected trends by school administrators }\end{array}$ & $\begin{array}{l}\text { Population Growth, Residential } \\
\text { Intensification }\end{array}$ \\
\hline 29 & Total No. of Schools & $\begin{array}{l}\text { New constructions adds schools while } \\
\text { selling old ones decreases the total number }\end{array}$ & New Construction, \% Sell PTR \\
\hline 30 & Total School GFA & Determined based on average school size & New Construction \\
\hline
\end{tabular}


Table 2: Key parameters and equations of the stock-and-flow simulation model

\begin{tabular}{|c|c|c|}
\hline Parameter & Unit & Model Equation / Description \\
\hline \$FRC & $\$$ & Facility replacement cost \\
\hline$\$ M_{t}$ & $\$$ & Maintenance expenditure at time $\mathrm{t}$ \\
\hline$\$ \mathrm{NC}_{\mathrm{t}}$ & $\$$ & New construction expenditure at time $\mathrm{t}$ \\
\hline$\$ \mathrm{R}_{\mathrm{t}}$ & $\$$ & Rehabilitation expenditure at time $t$ \\
\hline$\%$ RL1 & $\%$ & $\%$ of rehab. budget allocated to rehab. level 1 \\
\hline$\%$ RL2 & $\%$ & $\%$ of rehab. budget allocated to rehab. level 2 \\
\hline CAPEX $_{t}$ & $\$$ & Capital Expenditure $=\$ M_{t}+\$ R_{t}+\$ N C_{t}$ \\
\hline D12 & No. of Facilities & Deterioration from good to fair $=D R 12 \times F C I_{\text {Good }}$ \\
\hline D23 & No. of Facilities & Deterioration from fair to poor $=D R 23 \times F C I_{F a i r}$ \\
\hline D34 & No. of Facilities & Deterioration from poor to critical $=D R 34 \times F C I_{\text {Poor }}$ \\
\hline D45 & No. of Facilities & Deterioration from critical to $\mathrm{PTR}=D R 45 \times F C I_{\text {Critical }}$ \\
\hline DR12 & {$[0,1]$} & Deterioration rate from good to fair $=T P 12 \times\left(\frac{1}{M F}\right)$ \\
\hline DR23 & {$[0,1]$} & Deterioration rate from fair to poor $=T P 23 \times\left(\frac{1}{M F}\right)$ \\
\hline DR34 & {$[0,1]$} & Deterioration rate from poor to critical $=T P 34 \times\left(\frac{1}{M F}\right)$ \\
\hline DR45 & {$[0,1]$} & Deterioration rate from critical to $\mathrm{PTR}=T P 45 \times\left(\frac{1}{M F}\right)$ \\
\hline FCI\%critical-fair & $\%$ & Different between FCI of state fair and critical $=32.5 \%$ \\
\hline FCI\%poor-fair & $\%$ & Different between FCI of state fair and poor $=12.5 \%$ \\
\hline $\mathrm{FCI}_{\text {Critical }}$ & No. of Facilities & $\int_{0}(D 34-D 45-R L 2) d s+F C I_{\text {Critical }}\left(t_{0}\right), \quad F C I_{\text {Critical }}\left(t_{0}\right)=105$ \\
\hline $\mathrm{FCI}_{\text {Fair }}$ & No. of Facilities & $\int_{0}(D 12+R L 1+R L 2-D 23) d s+F C I_{\text {Fair }}\left(t_{0}\right), F C I_{\text {Fair }}\left(t_{0}\right)=35$ \\
\hline $\mathrm{FCI}_{\text {Good }}$ & No. of Facilities & $\int_{0}^{\tau}(N C-D 12) d s+F C I_{\text {Good }}\left(t_{0}\right), \quad F C I_{\text {Good }}\left(t_{0}\right)=31$ \\
\hline $\mathrm{FCI}_{\text {Poor }}$ & No. of Facilities & $\int_{0}^{l}(D 23-D 34-R L 1) d s+F C I_{\text {Poor }}\left(t_{0}\right), \quad F C I_{\text {Poor }}\left(t_{0}\right)=258$ \\
\hline FCI $_{\text {PTR }}$ & No. of Facilities & $\int_{0}^{\imath}(D 45-F S) d s+F C I_{P T R}\left(t_{0}\right), \quad F C I_{P T R}\left(t_{0}\right)=9$ \\
\hline $\mathrm{FS}_{\mathrm{t}}$ (Facility Sell) & No. of Facilities & Number of sold facilities at time $t$ \\
\hline MF (Maintenance Factor) & Factor $[0.1,1]$ & {$[0.1,1]$} \\
\hline $\mathrm{NC}_{\mathrm{t}}$ (New Construction) & No. of Facilities & Number of constructed new facilities at time $t$ \\
\hline $\mathrm{N}_{\text {Total }}$ & No. of Facilities & Total number of schools \\
\hline Overall FCI & {$[0,100]$} & Average of the network FCI values \\
\hline Overall FRI & {$[0,100]$} & $\left(\Sigma\left(\frac{F C I_{j t}}{N_{\text {Total }}}\right) \times p_{j}\right) \times U R_{t} \times \frac{\text { Network Age }}{100}$ \\
\hline Over-Capacity & N/A & $\operatorname{Max}\left(U R_{t}-1,0\right)$ \\
\hline $\mathrm{p}_{\mathrm{j}}$ & $\%$ & Probability of failure for facilities in FCI state $\mathrm{j}$ \\
\hline \multirow[t]{2}{*}{ RL1 (Rehab. Level 1) } & \multirow[t]{2}{*}{ No. of Facilities } & $\underline{\% R L 1 \times \text { Rehab. Budget }}$ \\
\hline & & $\begin{array}{l}\text { FCI } \%_{\text {Poor }- \text { Fair }} \times \$ F R C \\
\% R L 2 \times \text { Rehab } . \text { Budget }\end{array}$ \\
\hline RL2 (Rehab. Level 2) & No. of Facilities & $\overline{F C I \%}{ }_{\text {Critical-Fair }} \times \$ F R C$ \\
\hline TLCC & $\$$ & $\int_{0}(\$ M+\$ R+\$ N C) d s$, initial value $=0$ \\
\hline TPmn & $\%$ & Transition probability from FCI state $\mathrm{m}$ to $\mathrm{n}$ \\
\hline $\mathrm{UR}_{\mathrm{t}}$ (Utilization Rate) & $\mathrm{N} / \mathrm{A}$ & total enrolment / total school capacity \\
\hline
\end{tabular}




\section{List of Figures}

Fig. 1: Research methodology for the proposed SD-based decision support framework

Fig. 2: FCI distribution for TDSB facilities

Fig. 3: Proposed causal loop diagram (CLD)

Fig. 4: Stock and flow diagramming notations

Fig. 5: Proposed stock and flow simulation model

Fig. 6: Calibration of deterioration rates (DRs)

Fig. 7: Model response to dynamic input tests

Fig. 8: Multi-variate sensitivity analyses results for FRI

Fig. 9: Policy simulation dashboard

Fig. 10: Effect of enrolment-based budgeting policies

Fig. 11: Policy optimization results 


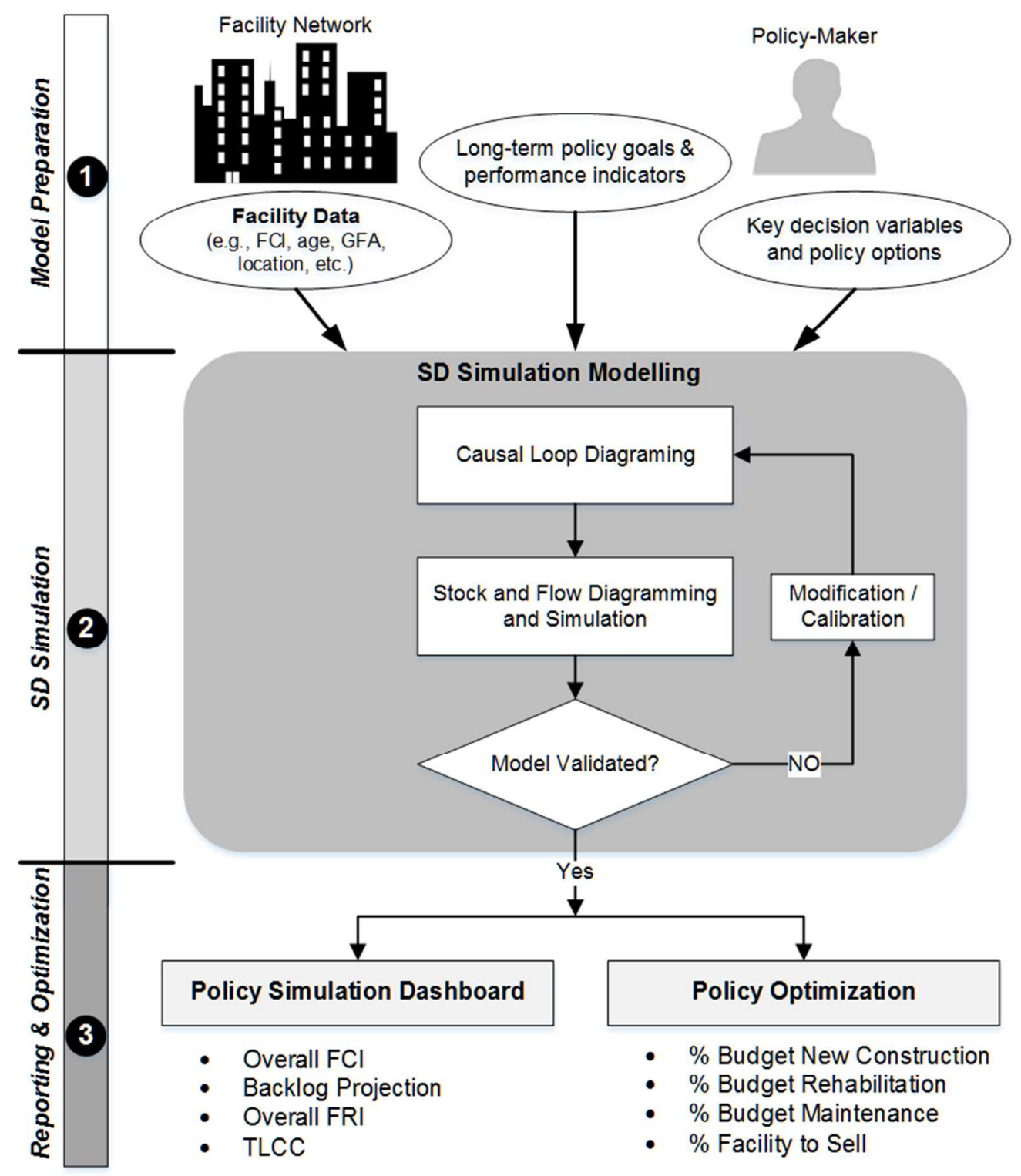

Fig 1

$146 \times 171 \mathrm{~mm}(144 \times 144$ DPI $)$ 


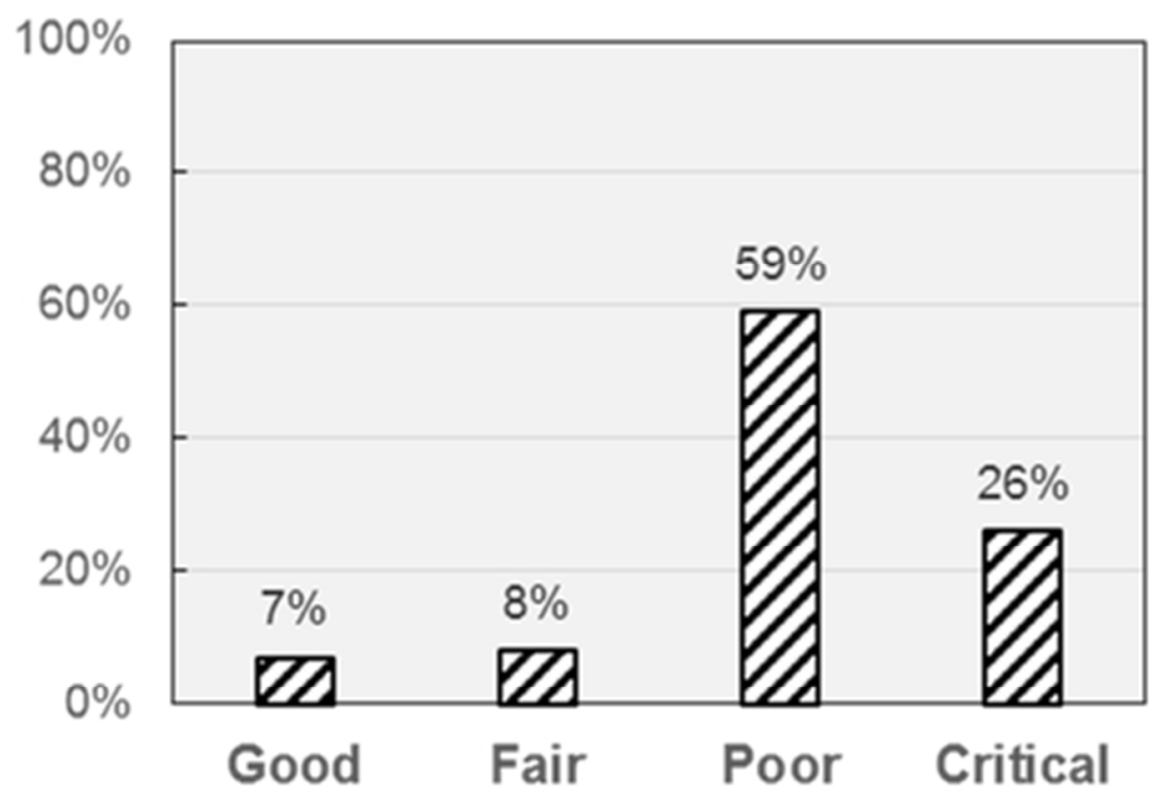

Fig 2

$82 \times 57 \mathrm{~mm}(144 \times 144$ DPI $)$ 


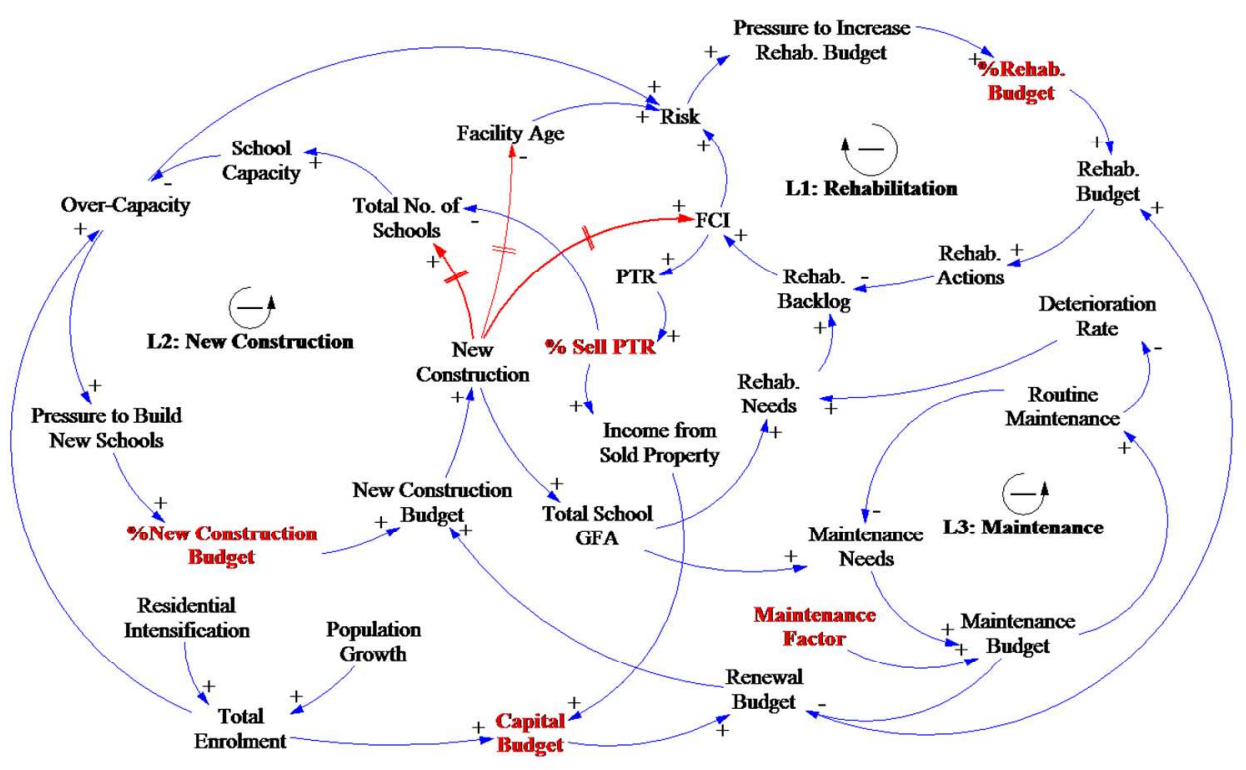

Fig 3

$252 \times 150 \mathrm{~mm}(144 \times 144 \mathrm{DPI})$ 

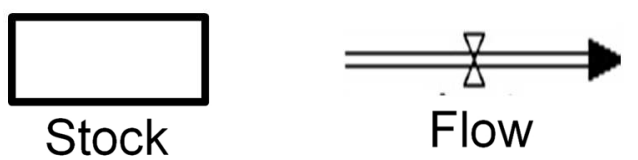

8

$\infty$

Stock

Valve

Cloud

Fig 4

$383 \times 67 \mathrm{~mm}(144 \times 144 \mathrm{DPI})$ 


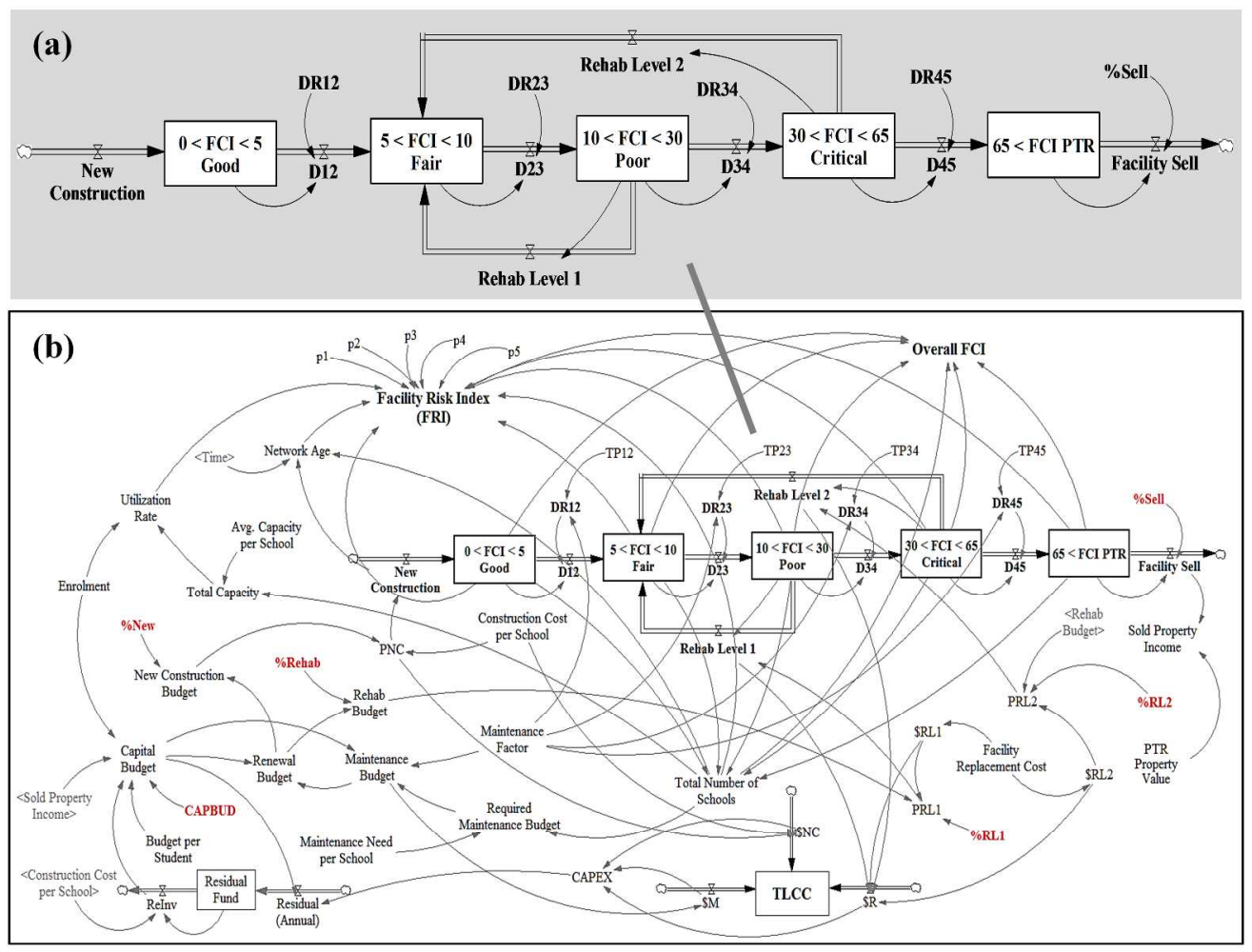

Fig 5

$629 \times 479 \mathrm{~mm}(144 \times 144 \mathrm{DPI})$ 


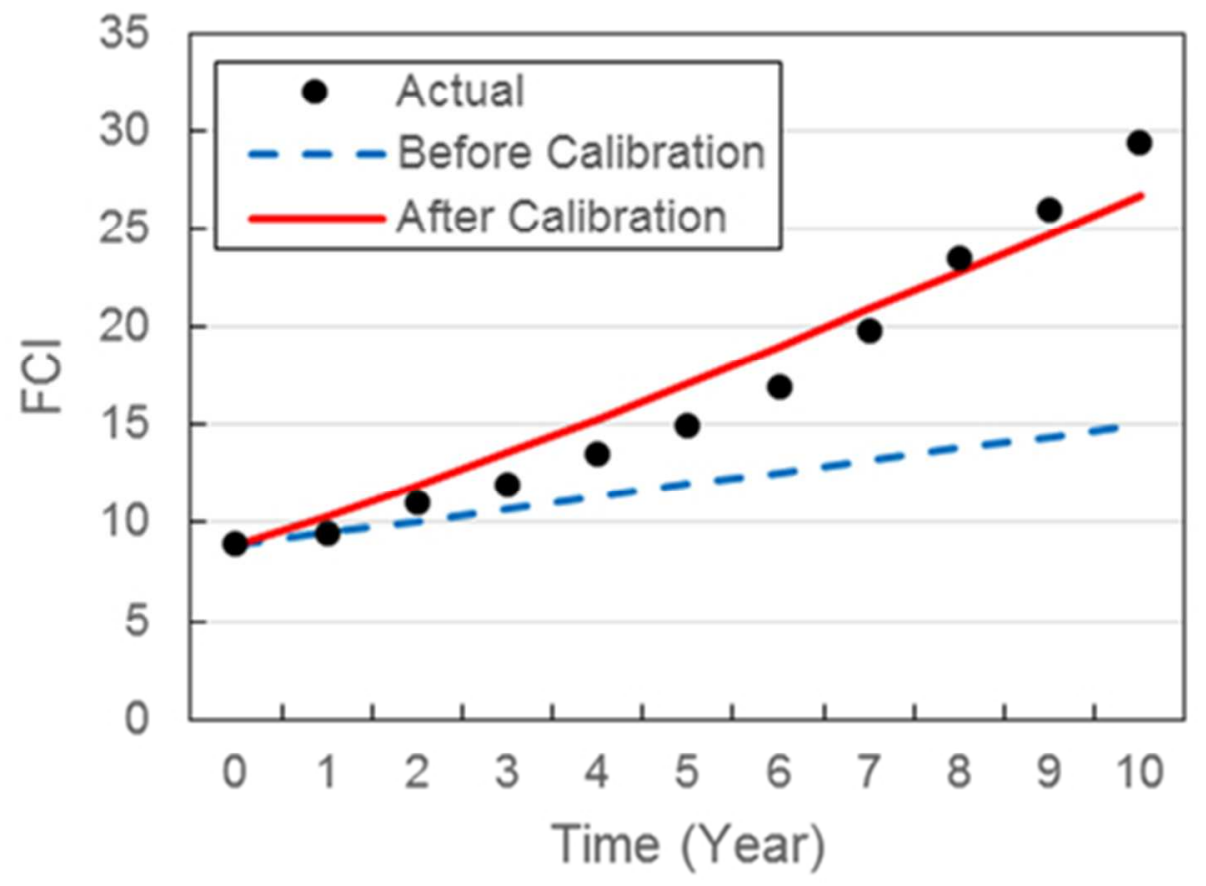

Fig 6

$89 \times 62 \mathrm{~mm}(144 \times 144$ DPI $)$ 
(a) RAMP Input

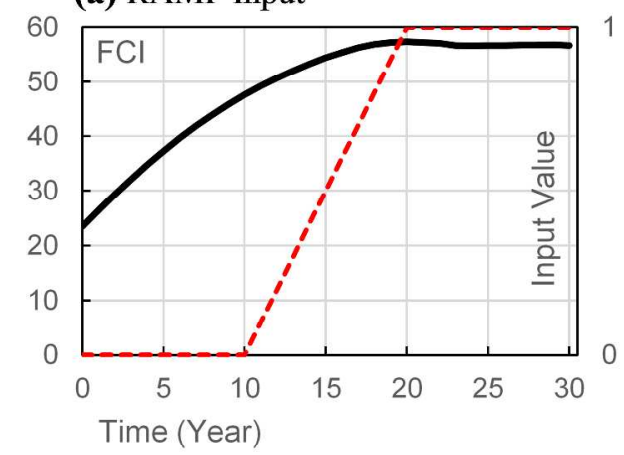

(b) STEP Input

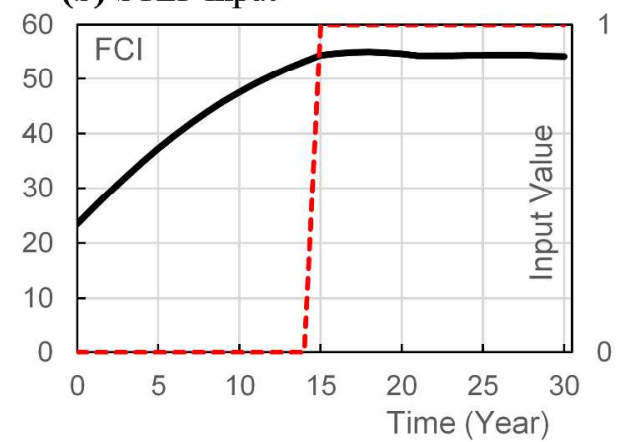

(c) PULSE Input

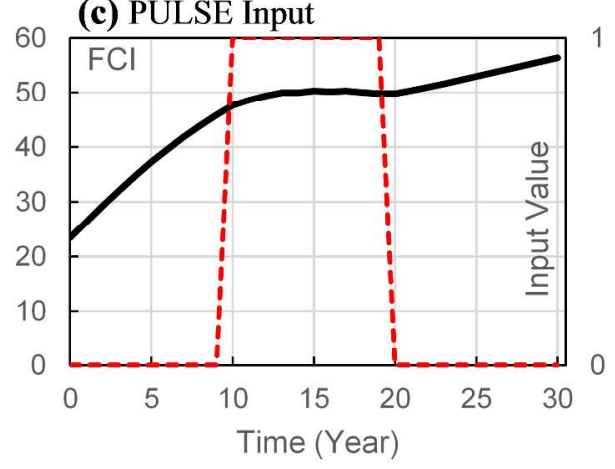

Fig 7

$614 \times 465 \mathrm{~mm}(144 \times 144$ DPI $)$ 
(a) FCI - 30\% \$FRC \& $\$ M N$

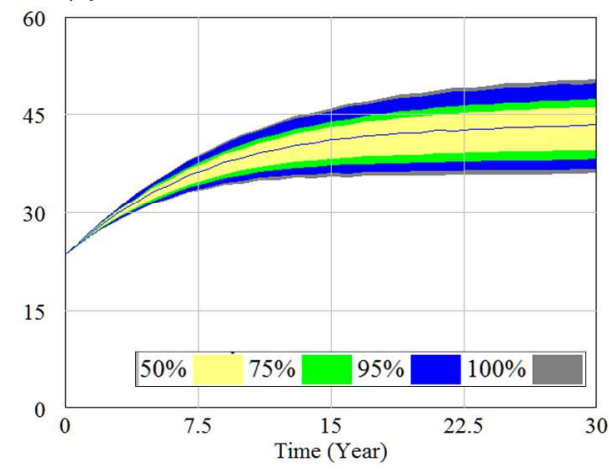

(b) FRI - 30\% \$FRC \& \$MN

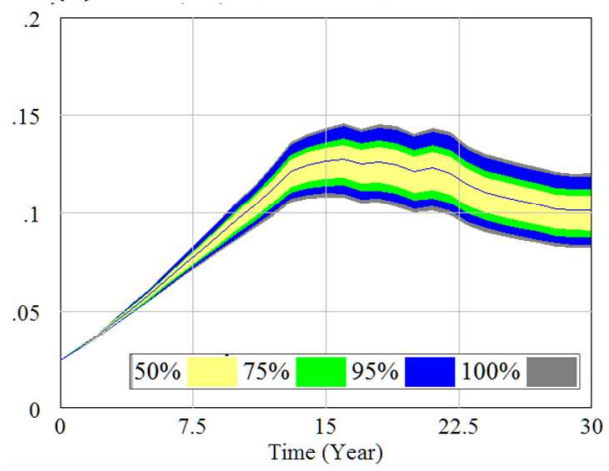

Fig 8 $630 \times 255 \mathrm{~mm}(144 \times 144$ DPI $)$ 


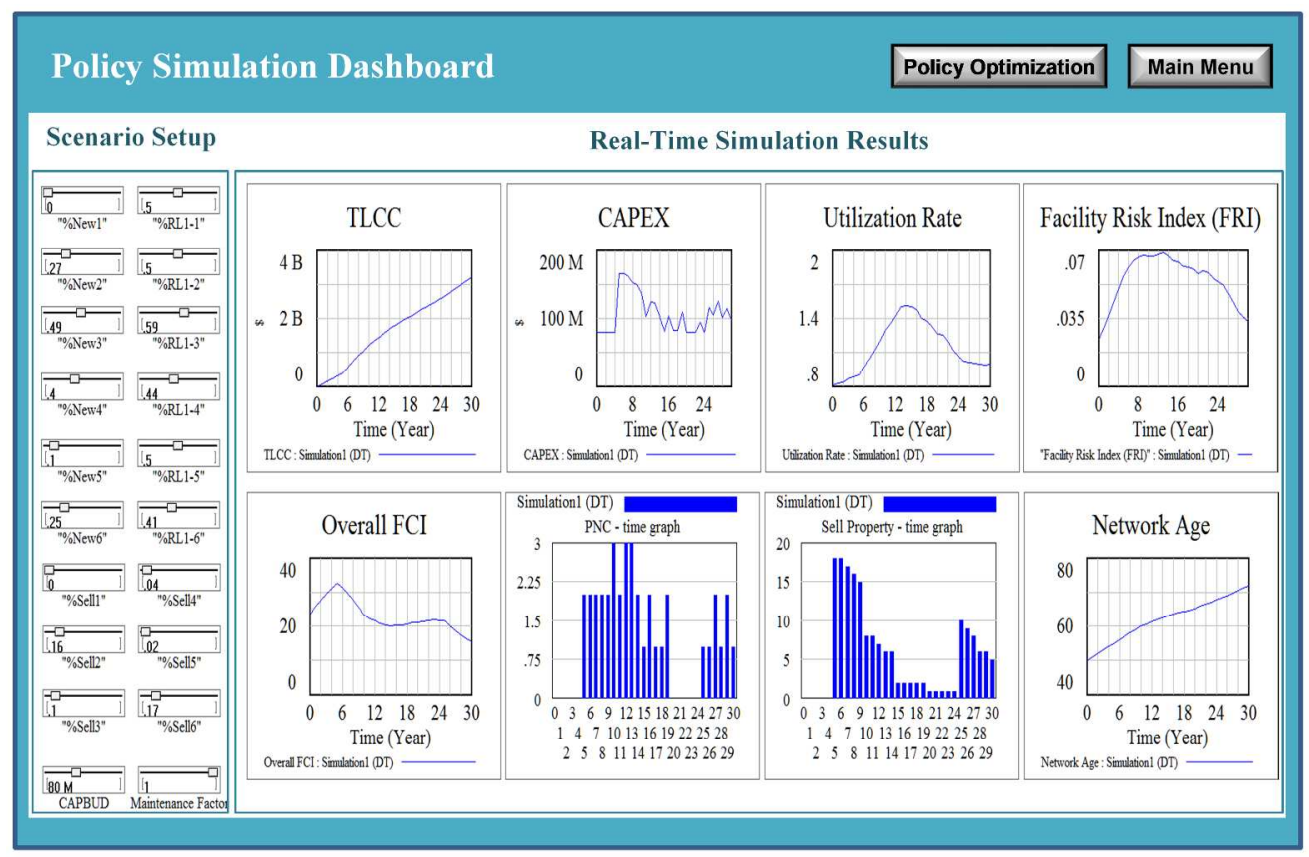

Fig 9

$647 \times 426 \mathrm{~mm}(144 \times 144 \mathrm{DPI})$ 
(a) Enrolment Trends

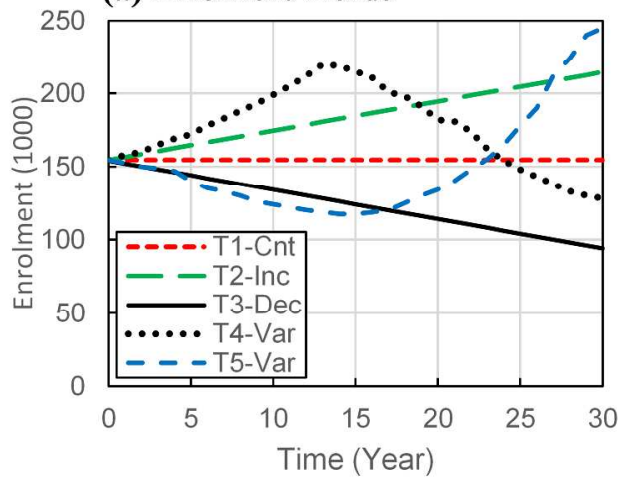

(c) Impact on the Overall FCI

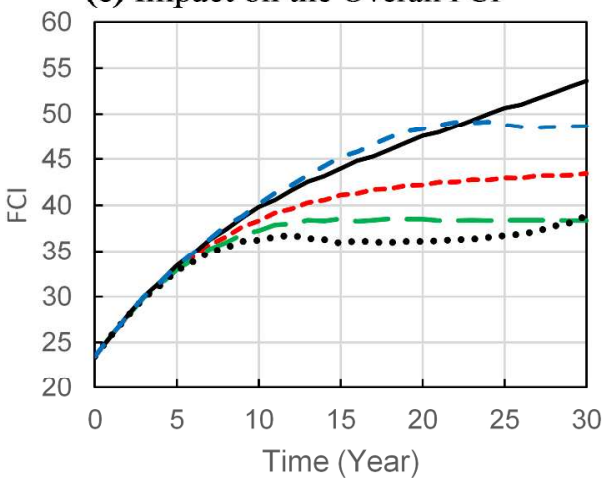

(b) CAPBUD (\$M)

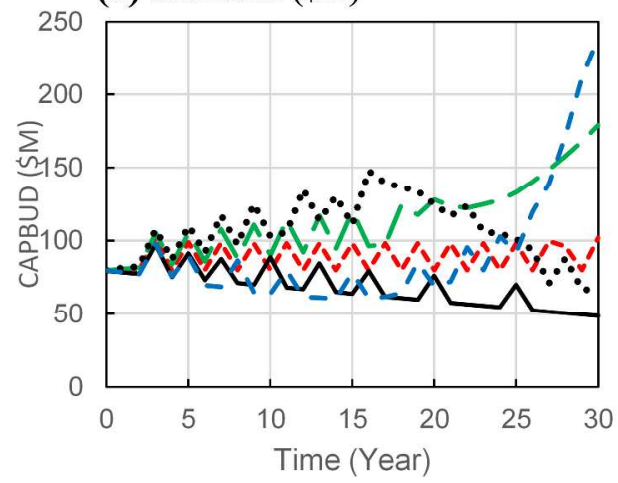

(d) Impact on the Overall FRI

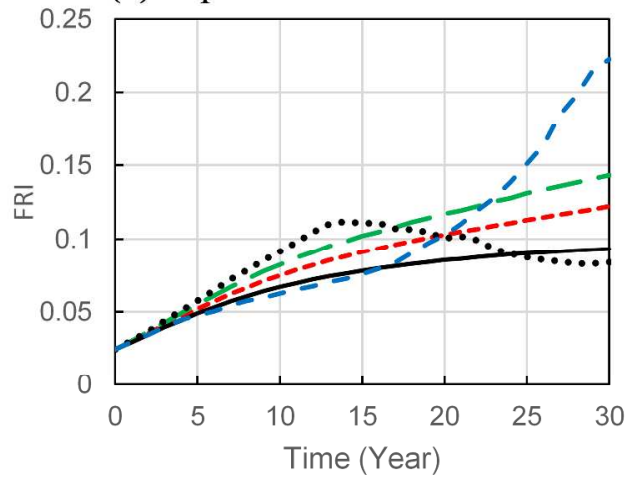

Fig 10

$636 \times 551 \mathrm{~mm}(144 \times 144$ DPI $)$ 
(a) Overall FCI

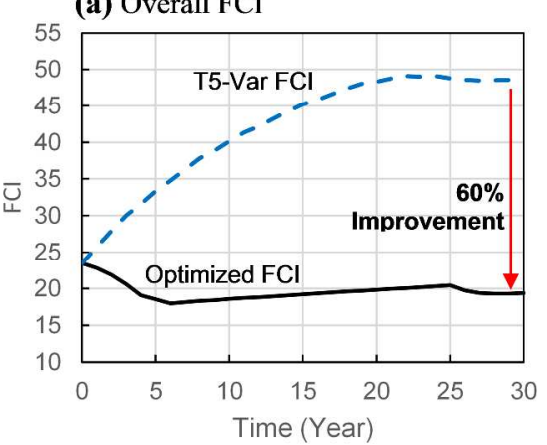

(c) CAPBUD (\$M)

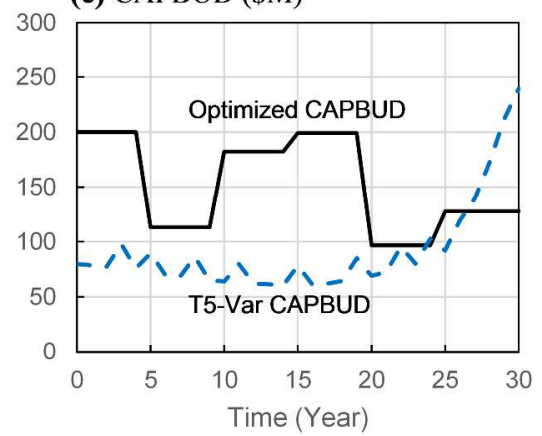

(e) Budget Allocation Variables

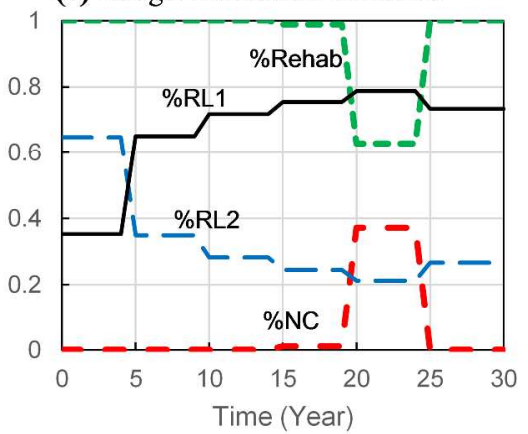

(b) Overall FRI

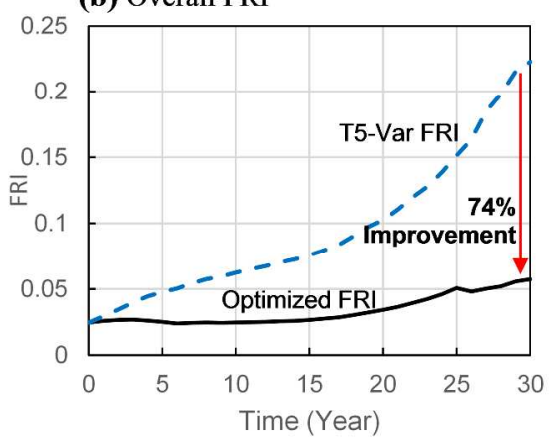

(d) CAPEX (\$M)

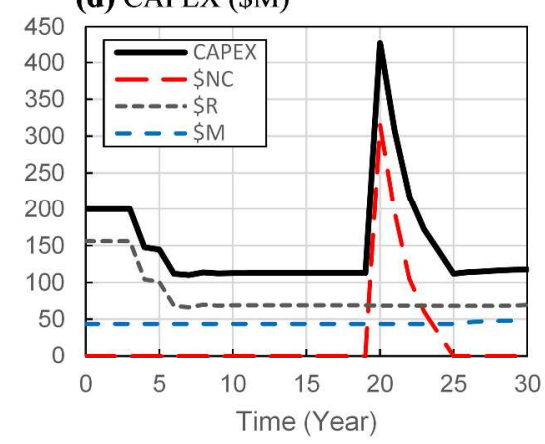

(f) FCI Distribution

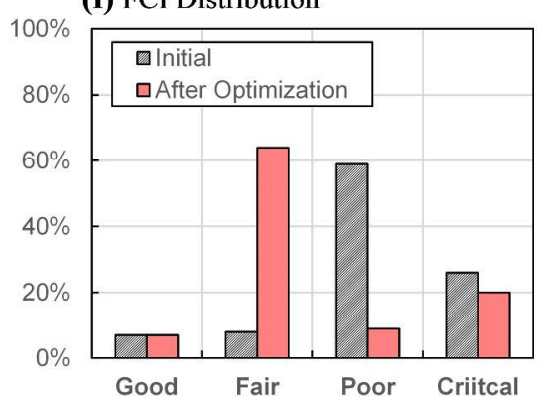

Fig 11

$631 \times 850 \mathrm{~mm}(144 \times 144$ DPI $)$ 